\title{
INVESTIGACIONES
}

\section{Formación de maestros y educación patrimonial*}

\author{
Teacher training and Heritage education
}

\author{
Andrés Domínguez Almansa, ${ }^{a}$ Ramón López Facal ${ }^{a b}$ \\ aDepartamento de Didácticas Aplicadas, Facultad de Formación del Profesorado, \\ Universidad de Santiago de Compostela \\ Telf.: (34) 600537462. Correo electrónico: andres.dominguez@usc.es \\ bTelf.: (34) 881812069. Correo electrónico: ramon.facal@usc.es
}

\begin{abstract}
RESUMEN
Se aborda el desarrollo de competencias profesionales de maestros en formación que han trabajado en aulas de primaria sobre el patrimonio presente en paisajes próximos, especialmente aquellos que suscitan conflictividad, como son los lugares de memoria asociados a la guerra civil española. Se trata de una investigación cualitativa de tipo interpretativo que ha compatibilizado el método etnográfico con el estudio de caso a partir de una muestra incidental de maestros que trabajaron colaborativamente. Los datos analizados proceden fundamentalmente de prácticas desarrolladas en aulas de educación primaria pero también se ha tenido en cuenta su formación previa en las aulas universitarias. Se comprueba que los maestros que han asumido y aprendido a desarrollar un modelo crítico del patrimonio, incorporando las dimensiones racional y emocional en la construcción de identidades, han sido capaces de aplicarlo a su alumnado de primaria, que, a su vez, ha desarrollado competencias sociales básicas.
\end{abstract}

Palabras clave: paisaje, apropiación patrimonial, competencias sociales.

\begin{abstract}
This paper deals with the development of professional skills on the part of trainee teachers carrying out work in the primary classroom on elements of heritage found in nearby landscapes, especially those which provoke conflicting points of view, such as sites associated with the Spanish Civil War. This research is qualitative and interpretive in nature and has made the ethnographic model compatible with the case study on the basis of an incidental sample of primary teachers working collaboratively. The data analysed is mainly taken from teaching practice carried out in the primary classroom, although the trainee teachers' prior experience at university has been taken into account. We have observed that the teachers who assumed and learned to develop a critical model of heritage, incorporating rational and emotional dimensions into the construction of identities, were able to successfully transmit these dimensions to their pupils, who, in turn, developed basic social skills in a successful way.
\end{abstract}

Keywords: landscape, appropriation of heritage, social skills.

\footnotetext{
* Este artículo forma parte de la investigación "Competencias sociales para una ciudadanía democrática” (EDU2015-65621C3-1-R) que ha contado con financiación del Plan Nacional de Investigación del Gobierno de España y del Fondo Europeo de Desarrollo Regional (FEDER).
} 


\section{INTRODUCCIÓN}

Partiendo de una concepción holística del patrimonio, que se ha venido aplicando en otros trabajos previos (Domínguez-Almansa \& López, 2014, 2015a, 2015b, 2015c, 2016, 2017a, 2017b), en esta investigación se amplía la tesis de que la competencia profesional de maestras y maestros en formación mejora al asumir una metodología contra-hegemónica aplicada a la educación patrimonial. Lo anterior implica incorporar la investigación en el entorno para propiciar prácticas innovadoras asentadas en una conciencia reflexiva. El análisis de los resultados durante la etapa de prácticas del profesorado permite constatar la mejora de la competencia docente al culminar un proceso formativo con el diseño y puesta en práctica de un proyecto orientado a la mejora de competencias sociales del alumnado sustentado en los conceptos metodológicos adquiridos.

El acercamiento al patrimonio se desarrolla a través de tres líneas que se entrelazan: a) el rechazo a proporcionar patrimonios predeterminados, sino a abrir procesos de apropiación en entornos próximos o alejados, desde el paisaje en su totalidad hasta elementos que lo integran; b) la voluntad de propiciar procesos de identificación como escenario para la construcción de identidades sociales inclusivas; c) incide en el papel que desempeñan en estos procesos de conocimiento lo racional y lo emocional, de forma no excluyente. Así, el conocimiento social permite despertar emociones que ponen en marcha mecanismos de identificación-apropiación que, a su vez, facilitan una mejor valoración del conocimiento social.

\section{EDUCACIÓN, IDENTIDAD, APROPIACIÓN PATRIMONIAL Y CONOCIMIENTO SOCIAL}

El patrimonio no reside en los objetos (Fontal, 2004, 2011), sino en un proceso de relaciones de pertenencia con algo: una relación entre posibles bienes y personas, confiriéndole una dimensión política. El reconocimiento patrimonial no queda al margen de disputas ideológicas en torno a su legitimación social mediante discursos identitarios (Estepa, Domínguez \& Cuenca, 1998; Prats \& Hernández, 1999). La educación patrimonial en las escuelas posibilita la apertura de procesos de identificación que valoren el conflicto como mediador de consensos socialmente más aceptables (Domínguez-Almansa \& López, 2015a). La identidad se reafirma mediante la oposición a un contrario (Hobsbawn, 2000), y frente a la identificación con un nacionalismo excluyente, el consumismo y el individualismo, se abre una oportunidad para la participación en la adquisición de una identificación con una cultura societal (Kymlicka, 2003). Este proceso, que pone el acento educativo en la valoración de las identidades societales o humanitarias, debe ayudar a transformar los valores en actitudes (Jiménez \& López-Zafra, 2011).

El proceso de identificación social es indisociable del de apropiación patrimonial. Promover una conexión con el entorno facilita al alumnado sentirse activo y creativo en la comunidad, estableciendo vínculos con un paisaje entendido como patrimonio en su totalidad o mediante los elementos que lo articulan: se facilitará así la construcción de conciencia ciudadana o identidades sociales (Busquets, 2010; Domínguez-Almansa \& López, 2014, 2015a). La educación a través del valor del paisaje puede contribuir a desvirtuar la extendida asociación consumo-felicidad (Ander-Egg, 2008; Domínguez- 
Almansa \& López, 2014). El paisaje pasa a ser una construcción social integrada por distintos elementos con potencial patrimonial, sin excluir los considerados no deseados o incómodos (Prats, 1997, 2005), o en conflicto, como en el caso de los procedentes de la identificación con las víctimas de la violencia política, generada en España por el franquismo, asumidas como símbolo de recuperación de memoria histórica para una representación ciudadana democrática. Las víctimas pueden reflexionarse como integrantes del patrimonio a la vez que se ponen en valor espacios monumentalizados o paisajes cotidianos ocultados asociados a ellas (Domínguez-Almansa \& López, 2016, 2017a, 2017b). Esto es aplicable a todo tipo de víctimas, no solamente de procesos de exterminio político, sino de la explotación económica, catástrofes medioambientales o luchas por la justicia social. Esos espacios de conflicto-apropiación patrimonial tienen la potencialidad de transcender el ámbito local para convertirse en localizados (Prats, 2005), ya que en torno a ellos establecen vínculos de pertenencia personas de muy distinta procedencia territorial.

Los procesos de identificación, básicos para la construcción de identidades que promuevan la acción colectiva de la ciudadanía en la reivindicación de derechos sociales y humanos, y los de apropiación patrimonial derivados de este aprendizaje, deben sustentarse en conocimientos que reinterpreten sus saberes: se debe favorecer que los escolares sean sujetos activos en la construcción de un presente mejor. El conocimiento tendrá que combinar criterios de racionalidad para que las emociones no se tornen banales o peligrosas, y hacer hincapié también en una dimensión emocional, imprescindible para consolidar un bien patrimonial (Prats \& Santacana, 2009a, 2009b). Se deberán promover contextos de indagación que muevan a la reflexión y en los que la adquisición de competencias sociales no suponga una disociación entre los saberes disciplinarios y la elaboración de propuestas éticas socialmente inclusivas. Cuesta $(2014$, p. 21$)$ propone acabar con las rutinas de la cultura escolar, reinventando su espacio en escenarios más propicios, virtuales o físicos, "que hagan posible un uso público del conocimiento histórico elaborado dentro del contexto de los centros educativos. Utilizando como método de análisis racional y emocional del presente la razón del sufrimiento de los vencidos". Una historia con memoria que integra la lucha y el sufrimiento (Cuesta, 2014, 2015).

El conocimiento social, encarnado en una historia con memoria que contradice las ficciones dominantes, facilita los procesos de identificación con el paisaje, y, en la medida que el paisaje permite entender las dinámicas del presente de un lugar en relación con su historia y la memoria de sus gentes, puede convertirse en sujeto de apropiación patrimonial. Todo patrimonio se configura y consolida con elementos inmateriales como la identidad y la memoria.

Estos supuestos se han aplicado en la formación de estudiantes de Magisterio de educación primaria (USC-Campus Lugo) desde 2013. Se ha venido desarrollando una investigación con la pretensión de valorar la capacidad del profesorado en formación para elaborar cooperativamente propuestas educativas acordes con una nueva forma de entender el patrimonio, demostrando su progreso en la adquisición de competencias profesionales que culmina en la aplicación de sus aprendizajes en las prácticas escolares reales con alumnado de primaria. Se ha tratado de comprobar el incremento de estas competencias reflejado en la capacidad de diseñar y aplicar proyectos basados en una educación en paisaje-patrimonio, y si han logrado que el alumnado de primaria los desarrolle. Entre ellas, además de la racionalidad crítica, la identificación emocional con elementos materiales e inmateriales presentes en los paisajes. Este objetivo se ha concretado en otros específicos para comprobar: 
- La capacidad del profesorado en formación de indagar en el medio para ofrecer un conocimiento más significativo a su alumnado y, al tiempo, desde el trabajo colaborativo, vincular investigación-innovación como práctica profesional.

- La apertura de procesos de apropiación patrimonial por el alumnado de primaria, valorando la importancia de lo inmaterial como sustanciador de los bienes patrimoniales.

- La apertura en el alumnado de primaria de procesos de identificación societal, al descubrir en el paisaje-patrimonio escenarios que recuperan memoria de la barbarie, la injusticia social o la lucha por la mejora de la condición humana.

- El cambio de significado del conocimiento social para el alumnado de primaria, mediante un cuestionamiento de las representaciones sociales sobre patrimonio.

\section{METODOLOGÍA}

La investigación se fundamenta en la tradición cualitativa (Flick, 2004) e interpretativa (Erikson, 1989). Se ha adoptado una perspectiva holística, integrando aspectos etnográficos (Creswell, 1998; Denzin \& Lincoln, 2005; Sandín, 2003) con estudios de caso (Stake, 1994). Se ha focalizado el proceso en la descripción y el análisis de los procesos en las aulas.

Se trata de una investigación longitudinal, con seguimiento de dos grupos de estudiantes de magisterio, de dos promociones diferentes. Durante el proceso previo en las aulas universitarias solicitaron poder trasladar los aprendizajes adquiridos a sus prácticas escolares. Se ha estructurado en dos bloques diferenciados, con dos fases cada uno. Se han analizado las actividades y resultados obtenidos en cinco colegios públicos rurales de la provincia de Lugo, abarcando de $3^{\circ}$ a $6^{\circ}$ cursos de primaria (entre 8 y 12 años de edad).

Los instrumentos para la obtención de datos en cada bloque han sido los diarios de observación del profesorado en formación (DO), narrativas individuales en las que reflexionan sobre el proceso llevado a cabo (RI) y distintas producciones del alumnado a su cargo. Tras constatar la importancia de los procesos educativos desarrollados a través de la interactuación mediante el diálogo en las aulas (Domínguez-Almansa \& López, 2014), se han realizado grabaciones que complementen la documentación escrita. Casi la totalidad de los materiales están en lengua gallega (se presentan traducidos). Se ha procedido a acotar los datos para reducirlos y hacerlos inteligibles, pero también relativizarlos para transformarlos y obtener resultados (García, 2003; Rodríguez, Gil \& García, 1999; Taylor \& Bogdan, 1984). No se han establecido categorías de análisis previas a la investigación, sino que una vez analizadas las producciones se han identificado aspectos relevantes que muestran la adquisición de competencias.

\subsection{PRIMER BLOQUE}

Dos experiencias continuadas en el tiempo (fases 1 y 2 ), en las que tres maestros y una maestra en formación en la fase 1 y tres maestros en la fase 2 diseñaron colaborativamente una actuación didáctica común durante el practicum de magisterio, readaptándola individualmente a los entornos en los que trabajaron durante dos cursos consecutivos con los mismos escolares. Cada maestro acompañó al mismo alumnado de un curso al 
siguiente. El proyecto se centró en los paisajes próximos, susceptibles de convertirse en un patrimonio en la medida que los escolares de primaria le confiriesen valor a través de la razón y la emoción. En la primera fase, el diseño fue producto de un mayor diálogo entre el profesorado en formación y su supervisor, aunque la concreción en cada contexto ha sido autónoma. En la segunda fase, únicamente se les planteó la idea de que su alumnado adquiriese más responsabilidades como difusor del conocimiento adquirido, pudiendo actuar como guías locales o divulgando su paisaje a través de una Wiki.

\section{Fase 1 (curso 2013-2014/ febrero-abril)}

Esta fase se llevó a cabo en cuatro colegios rurales. El profesorado en prácticas se tuvo que adaptar a un ámbito marcado por el declive demográfico: C1 (11 escolares de $4^{\circ}$ curso y 4 de $\left.6^{\circ}\right)$; $\mathrm{C} 2\left(9\right.$ de $\left.4^{\circ}\right)$; $\mathrm{C} 3\left(3\right.$ de $3^{\circ}$ y 8 de $\left.4^{\circ}\right)$; $\mathrm{C} 4\left(24\right.$ de $\left.5^{\circ}\right)$. A C 4 , aunque con rasgos urbanos, acude alumnado de ámbitos rurales próximos.

a. Se solicitó una narrativa sobre qué lugares de la localidad y de Galicia enseñarían y cuáles no, a una persona foránea (Narrativa Inicial-NI).

b. Mediante diaporama, se mostraron paisajes de los otros centros implicados, indicando que cada uno trabajaría con su paisaje. Se utiliza la ventana del aula para comenzar a descubrir el paisaje y reflexionar sobre si habría algo que enseñar. Se propuso la realización de una actividad similar a la de otros colegios, como una salida de campo.

c. Salida. Se establecieron grupos para compartir, de forma colaborativa, reflexiones espontáneas o generadas por preguntas-respuestas guiadas. Se obtuvieron fotografías para incentivar capacidades exploratorias y de percepción.

d. Se recurrió, mediante materiales gráficos y textos, a la provocación de imágenestemas generadores (Freire, 1988), contextualizando sus paisajes locales en los de Galicia; contrastando estereotipos como la asociación rural-natural o la exclusividad de la monumentalidad y de lo "bonito"; atendiendo al dinamismo de los paisajes con predominio de elementos naturales (Cíes, Monte Pindo), o culturales (Castro de Baroña, casco histórico compostelano) e integrando otros, producto de catástrofes provocadas por la acción humana como incendios forestales y vertidos petrolíferos.

e. Tras las vacaciones de primavera, se estableció un diálogo sobre lugares visitados y los paisajes percibidos.

f. Narrativa final (NF), con idéntico tema que la inicial.

\section{Fase 2 (curso 2014-2015/ septiembre-noviembre)}

No participó el C1. Se desarrolló en el C2 (10 de $\left.5^{\circ}\right)$; C3 (8 de $\left.5^{\circ}\right)$; C4 (14 de $6^{\circ}$ : por razones organizativas, el alumnado procedente de $5^{\circ}$ había sido dividido en dos grupos en $6^{\circ}$ curso).

a. Tras recordar la experiencia del curso anterior a través de imágenes y lecturas de algunas narrativas, se reflexionó sobre paisajes vividos durante el verano.

b. Se proporcionaron materiales para, tras un contraste de opiniones, elaborar colaborativamente una salida y guiar a alumnado de otro curso, diseñando un 
itinerario con elementos geográficos, históricos y sociales.

c. Salida de campo con una puesta en escena similar al curso anterior; pero el alumnado tuvo que desempeñar el papel de guía/docente de otro curso del centro (C2 curso inferior; C3 curso superior; C4 igual curso e inferior).

d. Elaboración colaborativa de una plataforma Wikispaces, adjuntando fotografías comentadas. Mediante una lectura actualizada de la idea de correspondencia escolar freinetiana (Inbernón, 2010) se procedió a un diálogo entre colegios sobre los materiales presentados y las experiencias vividas.

e. Narrativas finales (NF II). El alumnado guía/docente tendría que referirse a lo que debería haber aprendido el alumnado guiado. A este, retomando el punto de partida de la fase 1, se le pidió que indicase lo que enseñaría y lo que no, de su localidad y de Galicia (Narrativas Alumnado Guiado-NAG).

\subsection{SEGUNDO BLOQUE}

Siguiendo el mismo procedimiento, se desarrollaron dos experiencias continuadas en el tiempo (fases 1 y 2), en las que dos maestros en formación compartieron la etapa de prácticas en un mismo centro rural. Un maestro acompañó al alumnado de $4^{\circ}$ a $5^{\circ}$ curso (15 en ambos cursos) y el otro de $5^{\circ}$ a $6^{\circ}(12)$. Diseñaron colaborativamente una actuación didáctica común para la que previamente investigaron los recursos del entorno. En este caso la actuación se centró en el paisaje y la memoria de las víctimas de la Guerra Civil, para lo que recurrieron a un monolito, algo alejado del colegio, en el que se recuerda a un grupo de personas asesinadas en 1937. Diseñaron y desarrollaron un proyecto en el que se incluía el memorial entre distintos elementos construidos del paisaje local: torre medieval, una escultura de un ciervo o una fuente con un grupo escultórico sobre la infancia. La propuesta didáctica radica en una educación nucleada por un posible patrimonio inmaterial y conflictivo como el de la memoria histórica. Al desarrollarse en el mismo centro, el trabajo colaborativo cobró aún mayor relevancia.

\section{Fase 1 (curso 2015-2016/febrero-abril)}

a. Comenzaron proyectando en sus aulas imágenes de cada uno de los hitos locales para comprobar el conocimiento, aceptación y significado que les otorgaba el alumnado.

b. Proyectaron imágenes sobre la fundación de un sindicato agrario local en el primer tercio del siglo XX; una composición con tres escenas: un fusilamiento, el grabado A derradeira lección do mestre (Castelao) y la foto de un maestro de la localidad asesinado en 1936 recordado en el monolito; otra composición con dos fotos de época en blanco y negro, una de mujeres hippies y otra de presas del franquismo; y una tercera con filas de personas huidas de España en 1939 y de Siria en la actualidad. Se le proporcionó a cada escolar un dosier con esas imágenes. Se formaron pequeños grupos para asociar cada imagen con una palabra.

c. Con la intención de que recurriesen a la memoria de sus allegados, tuvieron que completar la tarea individualmente en sus casas, recogiendo por escrito lo que representaban las composiciones y las emociones que suscitaron.

d. Realizaron un itinerario por la localidad para contextualizar procesos de la historia 
local, algunos relacionados con las imágenes trabajadas, especialmente el monolito memorial.

e. Los maestros en formación, retomando la primera actividad, pudieron comprobar mediante una puesta en común la identificación del alumnado con los monumentos, sus razones, si cambiarían algo y si les interesaba que la memoria del sufrimiento estuviese presente en su localidad.

\section{Fase 2 (curso 2016-2017/ septiembre-noviembre)}

a. Comenzaron comprobando qué se recordaba de lo trabajado el curso anterior, y de qué manera.

b. Se solicitó al alumnado que explicasen lo que más les había impactado de lo aprendido el curso precedente. En $5^{\circ}$ trabajaron por parejas elegidas libremente para preparar materiales que convirtieron en guiones para representar ante la clase y grabarlos en video.

c. Se trató de un proceso más dilatado. Integró al alumnado de ambos cursos ensayando una obra de teatro inspirada en sus emociones y escrita por los maestros en prácticas quienes decidieron que, ya que estaban en un Centro Público Integrado (CPI), sería conveniente representarla para estudiantes de $3^{\circ}$ y $4^{\circ}$ cursos de Educación Secundaria (14-16 años) y grabarla en video. Concluiría el acto con un diálogo entre el alumnado de primaria y secundaria.

\section{PRÁCTICA Y COMPETENCIA}

\subsection{COMPETENTES CONOCIENDO Y TRANSFORMANDO (B-1: FASE 1)}

Se han seleccionado datos significativos para comprobar el desarrollo de competencias, identificando los aspectos más relevantes durante el proceso en el que trataron de identificar las representaciones del alumnado de primaria, desde la banalidad inicial, y valorar cómo y en qué medida se transformaban.

Conocer y analizar las representaciones del alumnado de primaria (Domínguez-Almansa y López, 2014)

Descubren la identificación con sus localidades o Galicia, pero excluyendo el paisaje o cualquier idea de patrimonio en el ámbito local, recurriendo a una realidad estereotipada. La identidad más significativa se manifiesta a través de espacios cotidianos banales: "lo llevaría a mi casa que tiene muchas cosas: televisiones, WII, DVD, juguetes" (NI-C2). "En Las Termas [centro comercial] hay un mogollón de tiendas como...” (NI-C3).

Me sorprendió mucho el hecho de que mientras [...] nos contaba que había visitado estos lugares con sus padres algún niño se riese, normalmente son niños muy respetuosos, pero ante esta situación yo pregunté cuál era el motivo de la risa y uno contestó que para él eso no eran lugares para ir de paseo, que prefería ir a un centro comercial [...], o quedarse en casa viendo una película. (DP -Maestra en formación [MF]-Colegio $1 \mathrm{C} 1$ ). 
Visión que se traslada al viaje a la playa hegemonizada por un puesto de helados, descartando lugares percibidos como peligrosos: "No enseñaría los ríos por si se caen, el bosque por si los pierdo de vista y tampoco los llevaría al monte que hay detrás de mi casa por si se pican con los tojos y zarzas" (NI-C1, $4^{\circ}$ ).

\section{Capacidad para concienciar del desconocimiento sobre lugares que afirmaban valorar}

“también pensábamos que conocíamos la provincia de Lugo y yo no sabía ni que en Parga había una torre, y voy todos los domingos a la feria" (DP-MF-C1).

\section{Capacidad para promover aprendizajes con resultados significativos}

"Creo que mis compañeros de proyecto y yo estamos logrando, no solo que el alumnado aprenda conceptos sobre el paisaje, sino que sepa usarlo como fuente de disfrute y de aprendizaje" (DO-MF-C3). Para hacerlo más atractivo, diseñaron una presentación que combinaba elementos del paisaje con personajes de ficción, pero comprobaron que se impuso el interés por elementos reales: "Cada vez que nos deteníamos en un elemento, salía gran cantidad de preguntas, hasta en algunos casos la imaginación cobraba fuerza [...] los llevaba a situarse en otra época de la historia" (Reflexión Individual [RI]-MF-C4). Han comprobado cómo este contexto de aprendizaje promueve nuevas reflexiones o actitudes: una alumna, al hilo de un debate suscitado al afirmar un compañero que un paisaje es bonito si hay gente, concluyó que cada momento tiene un paisaje indicado (DP-MF-C3); o "mi casa está restaurada y yo la enseñaría; o "¡Ah, por cierto! En mi pueblo hay un castro, pero no es igual a los que vimos. Este está sin excavar [...] Al hablar de los castros en clase, y como no queda lejos de mi casa, en las vacaciones fui a verlo" (DP-MF-C4), o al trabajar sobre acciones antrópicas devastadoras "demostraban una conciencia plena del paisaje, como si los estuviesen dañando o hiriendo a ellos" (DP-MF-C2).

\section{Lo más relevante: haber demostrado capacidad para generar autónomamente contextos de} apropiación patrimonial en correlación con procesos de identificación social

Teniendo en cuenta la visión consumista de la playa mostrada en las narrativas iniciales, han reflexionado sobre los efectos en su alumnado al contemplar una playa petroleada tras el desastre del Prestige. ¿Podrían consumir allí helados? Además de asumir una nueva valoración del paisaje, les llamó poderosamente la atención la masiva afluencia de personas voluntarias para limpiar playas y acantilados, lo que permitió abordar la solidaridad para afrontar situaciones injustas. Un alumno comentó que sus padres estaban entre esos voluntarios, provocando el aplauso del grupo. Grupo que, en la salida de campo en la que se ponía en valor el río local, procedió espontáneamente a limpiar un espacio de desperdicios (DO-MF-C4). Un espacio irrelevante cobró especial notoriedad al ser entendido como escenario de una masacre durante la Guerra Civil "Una cuestión que les llegó muy dentro. No pensé que fuesen a reflexionar tanto y tan bien respecto a esto" (DO-MF-C2). Por otra parte, el alumnado del C3 mostró su enfado al comparar el estado de la torre medieval de la localidad al contrastarla con las del C2 o C4. Pero "hablamos de los Irmandiños [...] Entonces el hecho de que nuestro castillo esté prácticamente destruido perdió transcendencia, porque había sido mandado a derribar por el abuso de los Parga a sus vasallos" (DP-MF-C3). 
Pudieron comprobar cómo su alumnado podía apropiarse de paisajes o espacios concretos mediante la empatía con protagonistas de diferentes acontecimientos históricos por los que tomaban partido.

\section{Capacidad para reflexionar sobre la experiencia llevada a cabo}

Se comprueba cómo las narrativas finales muestran una trasformación de sus representaciones (Domínguez-Almansa \& López, 2014). Inicia la identificación con espacios de ocioconsumo que en ocasiones se rechaza explícitamente: "no les enseñaría centros comerciales porque ya los hay en el lugar de donde vienen" (NF-C1). Frente a las visiones estereotipadas, se produce una incorporación razonada de paisajes dominados por elementos naturales o construcciones humanas dignos de ser visitados, adquiriendo significados nuevos, en relación con el conocimiento social o histórico "los castros porque son restos de casas muy antiguas" (NF-C2); "un paisaje, que me gusta y que hice una excursión [...] las casas muy antiguas como el castillo casi destruido por los Irmandillos" (NF-C3). Sin embargo, han comprobado también cómo aspectos muy bien valorados colectivamente, caso del voluntariado que hizo frente al desastre del petrolero Prestige, no se incorporaron en el común de las narrativas, excepto entre la representación de alumnado de $6^{\circ}$ curso (4), para quienes una playa que estuvo petroleada sería visitada como lugar de memoria, para recordar que "vinieron personas de todo el mundo a ayudar" (NF-C1).

\subsection{COMPETENTES INCENTIVANDO ACTUACIONES COOPERATIVAS (B-1: FASE 2)}

En esta segunda fase los maestros en formación tenían el cometido de redimensionar y asentar el proceso iniciado el curso anterior.

Capacidad para conocer y analizar en qué medida la experiencia (fase 1) había surtido efecto

Teniendo además en cuenta que las narrativas finales no acababan de reflejar en toda su intensidad lo acontecido en las aulas. "...me sorprendieron gratamente" (DO-MF-C2); "aunque pase el tiempo [...] siguen recordando, fruto de la experimentación" (DO-MF-C4).

\section{Capacidad para redimensionar su propio trabajo colaborativo como maestros}

Teniendo en cuenta que todas las localidades en las que se encuentran los centros cuentan con torres medievales en ruinas y que la apropiación más significativa por parte del alumnado se produjo en el C3, en relación con las revueltas irmandiñas, decidieron hacer de esta relación una nueva forma de acometer este elemento y comprobar sus resultados. También asumieron colectivamente una actividad llevada a cabo en el C3 que había despertado interés: conocer que el maíz y la patata eran productos foráneos, cuya exitosa incorporación transformó el paisaje y la sociedad gallega. Irmandiños y cultivos se convirtieron en ejes vertebradores de la fase 2. A esto se suma la capacidad para diseñar trabajo cooperativo para el alumnado. Teniendo en cuenta el interés del alumnado por las salidas, les encomendaron preparar una para que actuasen de guías de otro alumnado del centro y, al mismo tiempo, mediante una Wiki, difundir lo que considerasen representativo de sus paisajes a otros centros que participaban de experiencias similares. "En el aula 
realizamos búsquedas en material bibliográfico e Internet. Se levantaban y cambiaban de sitio. Hablaban de lo que encontraban y descubrían [...] Todo en un aparente caos o anarquía pedagógica, pero en realidad sorprendentemente eficaz" (DO-MF-C3); "el lema del trabajo siempre fue: ¡Somos un equipo! [...] todo era en beneficio de la comunidad" (DO-MF-C4); "eran pocas las veces en que un niño elegía una imagen porque sî́" (DOMF-C2); "La necesidad de un único pie de foto [Wiki] se convirtió en interesante práctica de democracia [...] ya que suelen tener dificultades para llegar a consensos" (DO-MF-C3).

Han sabido estimular y comprobar cómo el alumnado, a medida que adquiere una valoración social de los paisajes de su entorno, se apropia de ellos

Acontece con las torres medievales presentes en todas las Wikis y narrativas escolares, y también con los Irmandiños, con los que se identificaron: "Torre de [...] símbolo de identidad de nuestra localidad" y "escudo de los nobles que apresaron al jefe Irmandiño" (Wiki C3); "una torre muy bonita y rota que los Irmandiños rompieron y luego construían casas" (respuesta C2 a Wiki C3); "Les explicamos en el castillo que los aldeanos se cansaron de tener que pagar impuestos [...] y destruyeron las murallas" (NF II-C2). En la salida de campo un alumno que explicaba como guía mostraba "una enorme identificación con los Irmandiños [...] Nadie se opuso, pues todos querían vencer a los señores [...] En algunos casos los identificaron con [...] un equipo muy modesto [de fútbol local] en contraposición con los grandes equipos de élite" (DO-MF-C4); "El pueblo salió a la calle y reclamó sus derechos decían algunos" (D.O-MF-C2). "A, que estaba escuchando todo esto, se le puso la piel de gallina" (DO-MF-C4). El mismo A señaló entre los elementos referenciales de su localidad "la historia de los Irmandiños" (NAG-C4).

El recurso del maíz y la patata les ha permitido comprobar la fascinación del alumnado al conocer que sus paisajes son producto de la historia y de incorporaciones llegadas de otros lugares. Lo que propició un interés por el origen o cambios de elementos de sus paisajes locales y por indagar sobre estos. "También cosas que son más gallegas que la muiñeira, el maíz y la patata, eran de fuera" (NF II-C4); "los niños gozaban de pisar el mismo suelo y beber de la misma fuente que nuestros antepasados, haciendo así la historia más palpable" (DO-MF-C3). En este contexto, al pasar por un espacio que acoge la feria, un niño cuyos padres se dedican a la venta ambulante "preguntó [...] ¿Cómo se vendía antes en la feria? ¿Cómo hacían? ¿Qué vendían?” (DO-MF-C4). Curiosidad bien reflejada en las Wikis: "Juzgados: antiguo hospital [...] estaba al servicio de los peregrinos" o "prisión [...] hoy museo de antigüedades" (C4) "Nos gustaría saber por qué se llama así el paseo" (Respuesta C2 a Wiki C4). Los escasos alumnos del C3, representantes de una Galicia rural en extinción, incluyeron entre su patrimonio: "El antiguo colegio de niñas [...] convertido en centro social" y "Centro de salud, antiguo colegio de niños".

Han comprobado cómo su alumnado se apropia de su entorno, criticando lo que lo daña.

¿Alguien sabe lo que había aquí?, pregunté: E dijo: el casino [...] ¿Alguien puede hacerme un análisis? [...] Una avalancha de ideas: S: está descuidado; N: no entiendo cómo está así, porque al estar en un sitio histórico no debería estar en este estado; $C$, $N$ y P: por dentro debe estar igual; $R$ : tenían que hacer que lo restauraran; $M$ : como pasan por aquí los peregrinos y para la gente de aquí, sería importante que lo hiciesen [...]. Unos comentarios enlazaban con otros y cada vez más. (DO-MF-C4). 
"Tenemos un río muy bonito, pero la gente no lo cuida como merece" (Wiki C4); "Un puñal en el corazón de los robles. (Wiki C3); "Construcciones de ladrillo que desentonan mientras vemos el gran paisaje al fondo" (Wiki C2).

\section{Han constatado cómo la actuación quedó reflejada en las narrativas finales del alumnado}

En estas, a excepción de un caso en el C2, se muestra un aprecio por espacios vinculados al paisaje-patrimonio, aportando explicaciones sustentadas en el conocimiento social. Por otra parte, el alumnado guiado muestra en sus narrativas diferencias respecto a las realizadas por sus guías al inicio de la primera fase. Disminuyó la intención de mostrar lugares relacionados con el consumo (desde más del $90 \%$ en las NI a menos del $50 \%$ en las NAG), y aumentó el interés por los espacios vinculados al paisaje-patrimonio razonados (desde menos del $25 \%$ en las NI hasta en torno a un $60 \%$ en las NAG).

\subsection{COMPETENTES CONOCIENDO Y TRANSFORMANDO (B-2: FASE 1)}

Este bloque se fundamenta en actuaciones desarrolladas en el aula de magisterio y en las de primaria (Domínguez-Almansa \& López, 2015c, 2016, 2017b), es relevante la experiencia del bloque 1 , tanto en lo que respecta al trabajo llevado a cabo autónomamente en C2 en torno al recuerdo de las víctimas (Domínguez-Almansa \& López, 2014, 2015a) como en el proceso de apropiación patrimonial producido en torno a las torres medievales en relación con la historia irmandiña. Los datos más significativos han sido presentados en un trabajo precedente (Domínguez-Almansa \& López, 2017a). Se muestran ahora más sintetizados y resignificados en relación con los del primer bloque.

\section{Capacidad para aprovechar especiales coyunturas del día a día}

"Día de la Mujer Trabajadora [...] que decidimos reivindicar [...] primera celebración en 1936, se reflexionó sobre la siguiente y que ocurrió en el período intermedio [...] nos serviría para la propuesta" (Reflexión Final Conjunta: RFC-DO-MF).

\section{Capacidad para descubrir y valorar las identificaciones patrimoniales del alumnado}

Los escolares aceptaron mayoritariamente la torre medieval por estar próxima, por su tamaño o antigüedad. En $5^{\circ}$ también aceptaron la estatua del ciervo por representar la naturaleza, y en $4^{\circ}$ una niña asocia la fuente alegórica de la infancia con su primera comunión, estimulando la memoria de otros. El monolito de las víctimas no despierta interés, por alejado, carente de atractivo y sentido, excepto para una alumna de $4^{\circ}$ que lo asocia con gente que "murió o mataron". La respuesta de esta alumna pone a prueba la capacidad del profesorado en formación para expresar opiniones críticas basadas en la experiencia y reflexiones en relación con la adquisición en competencias sociales:

Su caso fue demoledor, los demás profesores/as la definían coma vaga y mentirosa. Que solo le interesaban las artes. Pasando por alto su sensibilidad hacia cuestiones sociales que manifestaba haciendo dibujos que asombraban a sus compañeros [...] Su respuesta me sirvió para comprobar que se premian los discursos y no las actitudes. (DO-MF-4º). 
Capacidad para utilizar estrategias didácticas que promueven reflexiones entre su alumnado

"gracias a la conciencia creada en la celebración del Día de la Mujer Trabajadora" (DOMF- $5^{\circ}$ ) su alumnado va dando sentido y significado al monolito identificándolo con la barbarie, bien centrándose en la fecha reseñada, 1937, o en nombres concretos, lo que estimula el interés investigador cuando las imágenes del pasado van cobrando sentido y despertando emociones. No sin dificultad, por ejemplo, en el caso de la imagen del asociacionismo agrario, en $4^{\circ}$ se recurre a que imaginasen que tuviesen que luchar por el recreo, tendrían más fuerza uniéndose. Con diferente impacto emocional, todas las imágenes les permiten acercarse al sufrimiento. Incluso una niña de $5^{\circ}$ pregunta al maestro en formación si él podría ser el maestro asesinado del monolito. En ambos cursos la experiencia evoca "miedo" y "tristeza" pero "no se acobardaban y querían saber más" con actitud "rebelde ante la injusticia" (DO-MF-4"; DO-MF-5; RFC).

Capacidad para conseguir que su alumnado dé sentido a la recuperación de la memoria, compartiendo imágenes del pasado y emociones con sus familias

La mayoría aporta comentarios que inciden en los conocimientos y emociones ya experimentadas. Dándose cuenta "del interés de la memoria de abuelas/os" (DO-MF-4; DO-MF- $\left.5^{\circ}\right)$, propiciándose puestas en común en torno a las víctimas. Una niña de $4^{\circ}$ reprodujo una frase de su abuela: "mi escuela fue el campo y mi maestra la azada". Esto, unido al hecho de que conoció a la hermana del maestro asesinado, motivó que la clase decidiese dejar su frase en el encerado como símbolo de la experiencia del franquismo $\left(\mathrm{DO}-\mathrm{MF}-4^{\circ}\right)$.

Capacidad para promover el espíritu crítico y la adquisición de competencias sociales vinculadas al patrimonio

"Yo me siento más unido a la torre porque la podemos ver cada día. El monolito es muy importante, pero está lejos". Siendo conscientes de la importancia del monolito no acaban de identificarse con él por lejanía y estética; sin embargo, sí con su significado, es decir con quienes sufrieron, proponiendo un monumento más atractivo y próximo: “...el cambio experimentado de cómo identificaban el monolito como patrimonio y que debía darse a conocer fue impresionante. Todos llegaron a la conclusión de que representaba mejor a la localidad que los otros monumentos" (DO-MF-4 $4^{\circ}$. "No se trata de poner una piedra y dejarla en el olvido, sino de hacer didáctica [...] Hay lecciones que se aprenden trabajando, y de los niños se aprende, solo hay que dejarlos hablar y escucharlos" (DO-MF-5 ${ }^{\circ}$; RFC).

\section{Desde el inicio de la experiencia, constataron que el tema iba más allá del tratamiento escolar normal}

Comenzando por no dejar indiferente a un profesorado en ejercicio, informado previamente por la dirección del centro. Antes de presentar la actuación: "mi tutora, jefa de estudios, preguntó por el tema [...] porque crea conflicto, intenté restarle importancia para no alarmar"; "preguntó por la propuesta, pero nunca la cuestionó". Frente a actitudes recelosas, 
los maestros en formación comprobaron cómo su actuación despertaba el interés más allá de la escuela. Así, en la salida de campo hegemonizada por la visita al monolito, contaron inesperadamente con la colaboración de un profesor de secundaria, la madre de un alumno de $5^{\circ}$ que lo estimuló para que llevase un trabajo escrito sobre lo acontecido y hasta del cura del lugar, partidario de recuperar la memoria.

\subsection{COMPETENTES INCENTIVANDO ACTUACIONES COOPERATIVAS (B-2: FASE 2)}

La segunda fase debería centrarse en una actuación en la que se incentivase la cooperación del alumnado de primaria ante la idea de difundir su visión del monolito. Lo que, al mismo tiempo, estimuló aún más las necesidades cooperativas de los maestros en formación y su consciencia de la importancia de esta forma de trabajar. Porque en este caso no se les proporcionó ninguna orientación. La decisión que tomaron desencadenó acontecimientos que reforzaron su desarrollo competencial.

Capacidad para conocer y analizar en qué medida la experiencia de la fase 1 había surtido efecto en su alumnado

[...] recordaban nombres de personas asesinadas [...] destacaba el maestro [...] fue terriblemente asesinado [...] les pregunté si recordaban cuál fue el motivo mediante el que descubrimos [...] por el día de la mujer trabajadora, ya que durante la dictadura no se celebró (DO-MF-5º); surgieron muchas respuestas y muy variadas [...] para ellos aquello tenía una importancia grande por lo trágico [...] A. dio pie a una visión nueva $[. .$.$] reivindicar lo sucedido [. .$.$\left.] gustó mucho. (DO-MF-6 { }^{\circ}\right)$.

Capacidad para promover estrategias mediante las que los escolares consolidan sus conocimientos, dándoles sentido y significado

Ante el reto de tener que contar lo que saben, sus reflexiones van desde la idea de víctima hasta lo que representó el franquismo:

Persona que no tiene culpa y que se acosa [...] acordaron definir la palabra víctima [...] otra que aparecía [...] fue patrimonio [...] que decidieron desarrollarla y hacerla propia: es una cosa o un lugar que representa algo de nuestra cultura comunitaria. Impresionante [... ] sobre todo la palabra comunitaria que A. sacó [...] La terminología que empleaban, lo explícitos que eran y lo bien que se expresaban me hizo sentir realizado. (DO-MF-6 ${ }^{\circ}$ ).

El alumnado de $5^{\circ}$ pudo ser grabado representando, en parejas, sus conocimientos y emociones más allá del aula $\left(G T S 5^{\circ}\right)$

[...] pude comprobar cómo interiorizaron el miedo a la figura de Franco y todo lo que representaba [...] también relacionarlo con la discriminación de las mujeres, quienes no pensaban igual, los pobres, el odio a la lengua gallega, los maestros que querían enseñar de un modo diferente [...] Lo que acaban de interpretar tiene mucho fondo y se puede observar con lo que se quedaron y les sorprendió [...] Pero quería que se 
sintiesen motivados y comenzasen a experimentar lo que supone interpretar esta temática a través del teatro [...].

Capacidad para generar un contexto de difusión y actualidad, tanto para las víctimas como para el hito erigido en su recuerdo

Mediante la preparación y representación entre ambos cursos de una obra teatral se han consolidado los aprendizajes e incentivado el trabajo cooperativo del alumnado y maestros en formación. En lo que respecta al alumnado de primaria, tres datos significativos:

conseguimos guiar sus investigaciones [...] para saber qué sucedía, cómo se vestían, las relaciones entre las personas, asimilar los roles que desempeñaban [...] surgiendo preguntas que se iban resolviendo por el diálogo [...] o diferentes búsquedas en la red (DO-MF-6 ${ }^{\circ}$ ); Si en algo no tuvimos que ver fue en la elaboración de materiales y vestuario elegido (DO-MF-5 ${ }^{\circ}$ ).

Al ver que los de sexto quedaban en los recreos de forma voluntaria, los de quinto me preguntaron si podrían hacer lo mismo conmigo [...] Quizás, al dar ejemplo y ser tú quien se queda en clase, acaban fijándose [...] Durante dos semanas previas [...] aunque cuando decimos que renunciaron al recreo [...] substituyeron el patio por el aula, ya que era un momento de alegría y diversión. (DO-MF-5).

El cambio que experimentó el alumnado de ambas clases en su relación de amistad. No acababa de gustarles tener que trabajar con otra clase [...] no habian aprendido a valorarse ni a trabajar en grupo (DO-MF- $5^{\circ}$ ). [Pero pronto] los de $6^{\circ}$ iban a enseñarle una actividad a los de $5^{\circ}[. .$.$] y esto sucedía a la inversa. (DO-MF-6 { }^{\circ}$ ).

Los maestros en formación fueron capaces de elaborar conjuntamente el guion de la representación teatral, teniendo en cuenta las emociones y demandas de su alumnado. Para acercar el monolito al colegio lo convirtieron en un árbol y las víctimas representaban el atentado a unos derechos humanos que iban colocándose en las ramas: "fue un trabajo laborioso, pero rodado, puesto que estar con un compañero [...] facilita mucho las cosas"

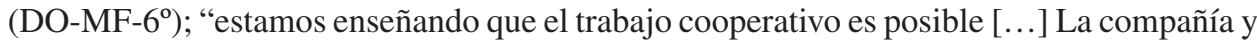
el apoyo de otra persona, el debate sobre puntos de vista y maneras de enfocar las actividades, provocó que esto llegase a buen puerto" (DO-MF- $5^{\circ}$ ). Trabajar cooperativamente también les sirvió para hacer frente a una nueva situación que surgió al solicitar que el alumnado de primaria representase la obra ante el alumnado de secundaria, profesorado y familias. Los maestros en formación descubrieron las dificultades de llevar al aula patrimonios en conflicto. A pesar de que su guion es una resignificación del monolito, un homenaje a las víctimas y un alegato a favor de los derechos humanos (GRT).

Fue curioso el cambio [...] cuando quisimos llegar más allá nos encontramos con impedimentos. El guion lo habíamos distribuido por cortesía a ciertas personas del centro y al día siguiente todo el claustro sabía por dónde caminábamos [...] Quisimos avisar a las familias [...] nos vimos censurados. La sensación fue de trabajar en la clandestinidad (DO-MF-6º); no puedo estar más de acuerdo con la frase de $R$. Luxemburgo, quien no se mueve no siente las cadenas. Por supuesto que las sentimos y las sufrimos [...] pero la clave está en resistir. (DO-MF- $\left.5^{\circ}\right)$. 
Capacidad para gestionar situaciones de conflicto derivadas de la aplicación de un método crítico

Consiguieron apoyos, incluyendo el de la maestra tutora de $5^{\circ}$ y de una profesora de secundaria. "Le gustó nuestro atrevimiento de llevar el tema a las aulas de primaria, pero más que lo transmitiesen a los mayores [... hizo posible que los de $3^{\circ}$ y $4^{\circ}$ de ESO viniesen" (DO-MF- $5^{\circ}$. Comprobando que se puede llegar a consensos que, aunque limitantes, mejoran las perspectivas iniciales. Así, la obra se representaría, pero estrictamente en

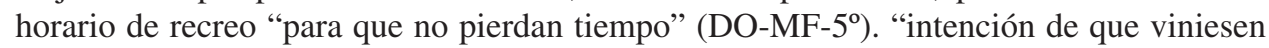
las familias [...] la dirección no lo recomendaba por las rivalidades que pudiese haber [...] Nos pareció una excusa un tanto cobarde [...] pero [...] vinieron a preguntarnos si podrían venir el día de la representación ante la insistencia de hijos e hijas" (DO-MF-5 ${ }^{\circ}$ ).

\section{Capacidad para enseñar y emocionar (GRT)}

Éramos mucha gente en un espacio tan pequeño [...] Iban a representar uno de los momentos más trágicos e injustos [...] y acabaron haciéndolo de una manera soberbia, emocionante, para ellos y para el público que quedaba abrumado cada vez que el telón corría [...] La grabación es una herramienta útil para mostrarlo, pero estar allí, viviéndolo fue una de las experiencias más alucinantes de mi vida. (DO-MF-6º).

La obra comenzó con una presentación, "Este va a ser un ejercicio de humanidad, un homenaje que no puede quedar en anécdota", en la cual aparecen derechos humanos mezclados con el pueblo y en torno a ellos se van representando los asesinatos de las personas recordadas en el monolito: derecho a organizarse, libertad de expresión, trabajo digno, igualdad de la mujer, derecho a la educación. Finalizando con una breve narración "Así de duro, así de injusto. Y en los libros leemos siempre que hubo dos bandos en una guerra de la que no se dan muchos datos". "Al finalizar [...] narradores/as hicieron una serie de preguntas a los de la ESO [...] si conocían la historia y su opinión [...] tenían que volver a las aulas y no pudo haber el debate que tanto nos gustaría" (DO-MF-5 ${ }^{\circ}$.

\section{RESULTADOS}

Ambas experiencias muestran la adquisición de competencias docentes del profesorado en formación, al utilizar entornos locales no hegemonizados por elementos de aceptada riqueza patrimonial (Griffin \& Eddershaw, 1996). Su práctica ha partido de una visión integral del patrimonio (Fontal \& Ibáñez, 2015; Ibáñez, Fontal \& Cuenca, 2015), focalizada en el paisaje (Liceras, 2003, 2013; Morón, 2013). Más que en el estudio de sus elementos objetivos, se ha prestado atención a que estos, singularizados o integrados en la propia realidad paisajística, puedan ser percibidos por el alumnado de primaria como sujetos de apropiación patrimonial. El patrimonio se configura como tal mediante sentimientos de pertenencia (Fontal, 2003) que generan contextos de conformación de identidad social (Martín, 2012). Desde esta perspectiva han desarrollado colaborativamente proyectos didácticos coincidentes con lo que Cuenca (2014) define como una adecuada educación patrimonial en la medida que han propiciado espacios para construir una ciudadanía 
comprometida. En este caso, generando en el alumnado de primaria procesos de apropiación-identificación de sus paisajes cotidianos en un escenario de aprendizaje social que integra lo racional y lo emocional como vehículo de transformación.

Los maestros en formación se han mostrado profesionalmente competentes al promover contextos educativos motivadores para un alumnado de primaria al que se propone acercarse al conocimiento social desde una perspectiva muy diferente a la que están habituados. En el caso de la segunda experiencia, la competencia de los maestros ha mejorado en la medida que han podido valerse de los resultados precedentes; pero también al comprobar y deber gestionar los problemas derivados de recurrir a la contramemoria para una didáctica crítica de la historia (Cuesta, 2007), centrada en la memoria histórica, el patrimonio y una enseñanza nucleada por las víctimas en relación con los derechos humanos (Domínguez-Almansa \& Santiago, 2014). Se quiso proyectar fuera del aula un conocimiento con una incuestionable carga emocional para integrar a la totalidad de la comunidad educativa. Esto les ha permitido constatar hasta qué punto ha calado la ficción del olvido en el contexto escolar, pero, al mismo tiempo, la valía del trabajo cooperativo para afrontarla, pudiéndose representar una obra de teatro cuyo guion muestra a su vez la competencia para ofrecer contenidos rigurosos no exentos de emoción.

La competencia profesional del profesorado también va ligada a las competencias sociales desarrolladas por su alumnado. En el caso de las dos fases de la primera experiencia, el alumnado cambió su identificación exclusiva y banal con espacios de su entorno asociados al ocio-consumo o a lo grande y lo bonito, para apropiarse conceptual y vivencialmente del paisaje, concretándose en elementos naturales como culturales: un árbol longevo; la riqueza del río que pasa por la localidad, que pierde valor en caso de estar contaminado; edificios a los que se les otorga valor social, incluso los que están en estado de abandono, pero que han descubierto como parte de la historia de la vida cotidiana local o escenarios de conflictos sociales con los que se identifican y toman partido. En la segunda fase han evidenciado los resultados del trabajo colaborativo, convirtiendo al alumnado en difusor de lo que se consideraba digno de valor. Se aprecia así un proceso de apropiación consciente del paisaje, que se ha desarrollado mediante una nueva valoración del conocimiento social, histórico, geográfico y emocional con el que han podido destacar bienes dignos de constituirse en patrimonios vividos y sentidos. Las ruinas de torres medievales presentes en los paisajes de referencia pasaban a ser valoradas más que por su antigüedad, belleza o monumentalidad, por haber sido escenario de las fallidas revueltas populares, provocando una identificación con las edificaciones en la medida que a través de ellas proyectaban miradas emocionadas hacia el pasado, fijadas en unos perdedores de la lucha por la justicia social, que en sus trabajos de difusión (Wikis) mostraban como campesinos percibidos como sus iguales.

Los datos de las dos fases de la segunda experiencia muestran cómo un monumento a las víctimas del exterminio político perpetrado en la guerra civil española ha pasado del absoluto desconocimiento por parte del alumnado, a que este sea capaz de valorarlo y reflexionarlo en función de lo que les ha aportado el conocimiento histórico y el trabajo con la memoria de sus mayores, capaz de suscitar razones y emociones. En la primera fase se puso en evidencia la apertura de un proceso de identificación-apropiación de unas víctimas que pudieron definir al comprender su contexto de victimización, dando más sentido al verdadero significado de la dictadura franquista y constatando que también podían acceder a su memoria desde su ámbito local. Pero, al mismo tiempo, se han mostrado críticos con el 
hito realizado en memoria de las víctimas, proponiendo alternativas que le confieran desde una nueva ubicación hasta una estética diferente. Este cuestionamiento del monumento como patrimonio material, unido a su plena identificación con las víctimas como patrimonio inmaterial, ha nucleado su trabajo en la segunda fase, en la que se han volcado, protagonizando un proyecto que les obligaba a esfuerzos intelectuales y emocionales. Desde la búsqueda de documentación hasta la apertura a un intenso trabajo colaborativo, que implicaba a alumnado de otro grupo. La necesidad colectiva de difundir el monumento a las víctimas, en este caso mediante una representación teatral, ha contribuido a darle un mayor significado y sentido al conocimiento de un proceso histórico focalizado en la realidad de quienes sufrieron, promoviendo un proceso educativo que entronca patrimonio y derechos humanos, como vía para la adquisición de competencias cívicas perdurables que puedan conformar identidades capaces de proyectar una sociedad más justa, que responda a la aspiración de Adorno (1998) de hacer del nunca más a la barbarie el enfoque más importante de la educación.

Las dos experiencias han mostrado la capacidad de los maestros en formación para enfocar sus proyectos docentes en consonancia con un concepto de patrimonio eminentemente dinámico, es decir, cambiante en función de las miradas que se proyectan en cada momento (Calaf \& Fontal, 2006). Pero aún más, en función de quién y para qué mira, porque las miradas son plurales y su proyección social no queda exenta de conflicto. Así, donde unos maestros pueden optar por mostrar la belleza o valor intrínseco del bien patrimonial, otros, como ha sido en este caso, buscan indagar si la conexión con un supuesto bien puede generar identificaciones con aspectos como la lucha por la justicia social, ambiental o los derechos humanos.

\section{CONCLUSIONES}

Los proyectos llevados a cabo por los maestros en formación han tenido su arranque en las aulas de magisterio, en las que han descubierto y se han adueñado de un universo crítico compartido entre la educación en paisaje y la patrimonial. Este marco de confluencia conformado por el protagonismo de las personas en función del conocimiento formal y la subjetividad, identificaciones, adhesiones simbólicas e identidades ofrece la posibilidad de construir o reconstruir socialmente cualquier entorno, tanto identificando y apropiándose de elementos que configuran paisajes de calidad, independientemente de su clasificación en los rankings de consumo, como cuestionando y apostando por la transformación de aquellos que traducen paisajes de la especulación, del abandono o de la memoria como instrumento para interiorizar cómo el sufrimiento humano se convierte en aspecto fundamental para comprender la sociedad.

Los maestros en formación han sido capaces de trasladar este concepto cívico del paisaje-patrimonio al alumnado de primaria en la medida que han logrado alcanzar razonablemente los objetivos específicos previstos. Su alumnado ha mudado sus representaciones sociales de un entorno sobre el que ha comenzado a ejercer apropiaciones patrimoniales, mientras como docentes han podido evaluar la importancia de lo inmaterial como elemento sustancial de los bienes patrimoniales. También han valorado la eficacia de los métodos de trabajo colaborativo para estudiantes y para unos docentes capaces de reflexionar y asumir la necesidad de investigar para conocer el entorno y la innovación- 
investigación como práctica profesional. Han valorado como problema educativo relevante descubrir en el paisaje aquellos elementos que recuperan hechos o memorias invisibles u ocultos, permitiendo a su alumnado adquirir conocimientos éticamente informados sobre el patrimonio material e inmaterial.

Consideramos que se ha cumplido el principal objetivo de la investigación. Así los maestros en formación han demostrado su competencia diseñando y aplicando proyectos basados en una educación en paisaje-patrimonio, que permita la adquisición de competencias sociales por el alumnado de primaria. Desde el estímulo de la racionalidad crítica a la identificación emocional con elementos materiales e inmateriales presentes en los paisajes estudiados y percibidos.

Tanto este estudio como otros que hemos realizado con anterioridad permiten avanzar en la idea de que el desarrollo de competencias profesionales del profesorado está relacionado con el desarrollo de sus propias competencias sociales, que le permiten proyectar distintas miradas sobre espacios, sujetos a su construcción social como paisajespatrimonios. Estas perspectivas didácticas abren una brecha en las rutinas profesionales reproducidas acríticamente e incorporan una nueva dimensión que les permite descubrir en el entorno un pasado, presente y futuro complejos. El hecho de que su alumnado aprenda a apropiarse críticamente del entorno, el hecho de descubrir que se identifican con quienes sufrieron o se rebelan -elementos reales que contrastan con las ficciones con las que se suele explicar lo social- o el hecho de que valoren el propio conocimiento social, los posiciona como profesionales activos en el marco de una educación comprometida con la construcción de una sociedad más justa.

Este trabajo no concluye aquí, sino que forma parte de un proceso en el que se está integrando una nueva promoción de profesorado en formación, que han asumido el compromiso de continuar esta experiencia. Pero en este caso su actitud se ha visto reforzada al poder haber trabajado en las aulas de magisterio con los maestros en formación que les han precedido. Concretamente, con los dos que han trabajado con la memoria, lo que ha facilitado que acaben de retornar de sus prácticas nueve maestras y maestros en formación, tres de ellas trabajaron en prisiones, con nuevas experiencias y, por lo tanto, la posibilidad de nuevos datos y más pruebas de la eficacia de estos planteamientos didácticos.

Como todo trabajo este también tiene sus limitaciones. La más destacada, que se han excluido datos y resultados, que más allá de la educación patrimonial, podrían ilustrar sobre la dimensión educativa de un cambio didáctico que prescinde de las rutinas y prácticas dominantes. Pero esta limitación no es irreversible, porque se cuenta con materiales que permiten abordar la cuestión, es, por tanto, prospectiva de trabajos futuros en los que además se aporten nuevos materiales para profundizar en la adquisición de competencias profesionales por parte de maestras y maestros en formación.

\section{REFERENCIAS BIBLIOGRÁFICAS}

Adorno, T. W. (1998). Educación para la emancipación. Madrid: Morata.

Ander-Egg, E. (2008). La ciudad educadora como forma de fortalecimiento de la democracia y de una ciudadanía activa y convivencial. Córdoba (Argentina): Brujas.

Busquet, J. (2010). La educación en paisaje: una oportunidad para la escuela. Iber. Didáctica de las Ciencias Sociales, Geografía e Historia, 65, 7-16. 
Calaf, R., \& Fontal, O. (Coords.). (2006). Miradas al Patrimonio. Gijón: Trea.

Creswell, J. (1998). Qualitative inquiry and research design: Choosing among five traditions. London: Thousand Oaks.

Cuenca, J. (2014). El papel del patrimonio en los centros educativos: hacia la socialización patrimonial. Tejuelo, 19, 76-96.

Cuesta, R. (2007). La enseñanza de la historia como contramemoria crítica. En S. Leoné y F. Mendiola (Coords.), Voces e imágenes en la historia. Fuentes orales y visuales: investigación histórica y renovación pedagógica (pp. 151-184). Pamplona: Universidad Pública de Navarra.

Cuesta, R. (2014). Genealogía y cambio conceptual: Educación, historia y memoria, Archivos analíticos de políticas educativas, 22(23). doi:10.14507/epaa.v22n23.2014

Cuesta, R. (2015). La venganza de la memoria y las paradojas de la historia. Salamanca: Lulu.com.

Denzin, N., \& Lincoln, Y. (2005). Introduction: The discipline and practice of qualitative research. In N. K. Denzin \& Y. S. Lincoln (Eds.), The Sage handbook of qualitative research (3rd ed., pp. 1-32). London: Thousand Oaks, Sage.

Domínguez-Almansa, A., \& López, R. (2014). Patrimonio, paisaje y educación: formación inicial del profesorado y educación cívica del alumnado de primaria. Clio. History and History Teaching, 40.

Domínguez-Almansa, A., \& López, R. (2015a). Patrimonio, entorno y procesos de identificación en la educación primaria. Clio. History and History Teaching, 41.

Domínguez-Almansa, A., \& López, R. (2015b). Paisajes invisibles, patrimonios en conflicto: experiencias en la formación del profesorado y la educación primaria. En A. M. Hernández, C. R. García \& J. L. De la Montaña (Eds.), Una enseñanza de las ciencias sociales para el futuro: Recursos para trabajar la invisibilidad de personas, lugares y temáticas (pp. 713-720). Cáceres: Universidad de Extremadura-AUPDCS.

Domínguez-Almansa, A., \& López, R. (2015c). Concepciones del alumnado de magisterio sobre la formación patrimonial. En G. Solé (Org.), Educaçâo patrimonial. Contributos para a construçâo de uma consciência patrimonial (pp. 117-132). Porto: Universidade do Minho.

Domínguez-Almansa, A., \& López, R. (2016). Invisible Landscapes - Heritage in Conflict: Memories of The Spanish Civil War: Elementary Education and Teacher Training. International Journal of Historical Learning, Teaching and Research, 14(1), 55-66.

Domínguez-Almansa, A., \& López, R. (2017a). Memoria histórica, patrimonio y formación del profesorado de educación primaria. En S. Molina, N. Llonch \& T. Martínez (Eds.), Identidad, ciudadanía y patrimonio. Educación histórica para el siglo XXI (pp. 71-86). Gijón: Trea.

Domínguez-Almansa, A., \& López, R. (2017b). Patrimonios en conflicto, competencias cívicas y formación profesional en educación primaria. Revista de educación, 375, 86-109.

Domínguez-Almansa, A., \& Santiago, B. (2014). La respuesta está en el viento: reflexión para una nueva docencia de la Guerra Civil. En L. Fernández y A. Artiaga (Eds.), Otras miradas sobre golpe, guerra y dictadura. Historia para un pasado incómodo (pp. 300-322). Madrid: La Catarata.

Erickson, F. (1989) Métodos cualitativos de investigación sobre la enseñanza. En M. C. Wittrock (Comp.), La investigación en la enseñanza II (pp. 195-301). Barcelona: Paidós.

Estepa, J., Domínguez, C., \& Cuenca, J. (1998). La enseñanza de valores a través del patrimonio. En Los valores y la didáctica de las ciencias sociales (pp. 327-336). Lleida: Universidad LleidaAUPDCS.

Flick, U. (2004). Introducción a la investigación cualitativa. Madrid: Paideia Galiza-Morata.

Fontal, O. (2003). La educación patrimonial. Teoría y práctica en el aula, el museo e internet. Gijón: Trea.

Fontal, O. (2004). La dimensión contemporánea de la cultura. Nuevos planteamientos para el patrimonio cultural y su educación. En R. Calaf \& O. Fontal (Coords.), Comunicación educativa del patrimonio: referentes, modelos y ejemplos (pp. 81-104). Gijón: Trea.

Fontal, O. (2011). El patrimonio en el marco curricular español. Patrimonio Cultural de España, 5, $21-41$. 
Fontal, O., \& Ibáñez, A. (2015). Estrategias e instrumentos para la educación patrimonial en España. Educatio Siglo XXI, 33(1), 15-32.

Freire, P. (1988). Pedagogía del oprimido. Madrid: Siglo XXI.

García, J. L. (2003). Métodos de investigación en educación. Investigación educativa (Vol. II). Madrid: UNED.

Griffin, J., \& Eddershaw, D. (1996). Using Local History Sources. Abingdon: Hodder \& Stoughton.

Hobsbawn, E. (2000). La izquierda y la política de la identidad. New Left Review, 0, 114-125.

Ibáñez, A., Fontal, O., \& Cuenca, J. (2015). Presentación. Actitud y tendencias en la educación patrimonial. Educatio Siglo XXI, 33(1), 11-13.

Inbernón, F. (2010). Las invariantes pedagógicas y la pedagogía Freinet cincuenta años después. Barcelona: Graó.

Jiménez, M. I., \& López-Zafra, E. (2011). Actitudes sociales y adaptación social en adolescentes españoles: el papel de la inteligencia emocional percibida. Revista de Psicología Social, 26(1), 105-117.

Kymlicka, W. (2003). La política vernácula. Nacionalismo, multiculturalismo y ciudadanía. Barcelona: Graó.

Liceras, A. (2003). Observar e interpretar el paisaje. Estrategias didácticas. Granada: Grupo Editorial Universitario.

Liceras, A. (2013). Didáctica del paisaje. Íber. Didáctica de las Ciencias Sociales, Geografía e Historia, 74, 85-93.

Martín, M. (2012). La comunicación y la comunicación patrimonial: una mirada desde el museo de Huelva (Tesis doctoral). Huelva, Universidad de Huelva.

Morón, M. (2013). Paisaje y Geografía: una oportunidad para educar en Patrimonio. En J. Estepa (Ed.), La Educación Patrimonial en la Escuela y el Museo: Investigación y Experiencias (pp. 237-247). Universidad de Huelva: Huelva.

Prats, J., \& Hernández, A. (1999). Educación por la valoración y conservación del patrimonio. Por una ciudad comprometida con la educación (pp. 108-124). Barcelona: Ayuntamiento de Barcelona.

Prats, J., \& Santacana, J. (2009a). La ciudad un espacio para aprender. Aula de Innovación Educativa, $182,47-51$.

Prats, J., \& Santacana, J. (2009b). Ciudad, educación y valores patrimoniales: La ciudad educadora, un espacio para aprender a ser ciudadanos. Iber. Didáctica de das Ciencias Sociales, Geografía e Historia, 59, 8-21.

Prats, L. (1997). Antropología y Patrimonio. Barcelona: Ariel.

Prats, L. (2005). Concepto y Gestión del Patrimonio local. Cuadernos de Antropología Social, 21, 17-35.

Rodríguez, G., Gil, J., \& García, E. (1999). Metodología de la investigación cualitativa. Málaga: Aljibe.

Sandín, M. P. (2003). Investigación cualitativa en educación: Fundamentos y tradiciones. Madrid: McGraw Hill.

Stake, R. (1994). Case Study. In N.K. Denzin \& Y.S. Lincoln (Eds.), Handbook of Qualitative Research (pp. 236-247). London: Sage.

Taylor, S. J., \& Bogdan, R. (1984). Introducción a los métodos cualitativos de investigación. Barcelona: Paidós. 